\title{
DESIGN E GÊNERO: O SEXISMO DENTRO DO UNIVERSO DAS RELAÇÕES CAPITALISTAS
}

\author{
Maria Eliane de Andrade Oliveira (discente)/UFPE \\ Virgínia Pereira Cavalcanti (orientadora)/UFPE
}

\section{RESUMO}

Este artigo discorre a respeito da discriminação direcionada as mulheres durante o desenvolvimento do capitalismo e os desdobramentos de uma divisão sexual do trabalho. Neste sentido, para melhor compreender o papel da mulher no período de transição do feudalismo para o capitalismo é que propomos uma análise a partir da obra, O calibã e a bruxa, da autora Silvia Federici. A revisão da obra é proposta a partir de uma perspectiva que considera as estruturas sociais e os aspectos históricos, que marcam as dinâmicas de consumo direcionadas a consumidores seguindo a binaridade de gênero. Pois, para entender o papel simbólico do consumo de "artefatos generificados" no espaço social, é necessário compreender os processos históricos que os determinam.

Palavras-chave: Design; Gênero; Capitalismo.

\section{Introdução}

Ao considerar as dinâmicas do consumo de artefatos voltados para a figura da "dona de casa", os quais carregam grande carga simbólica de representação do papel da mulher na sociedade patriarcal, é fundamental destacar o processo de desenvolvimento capitalista. Para isso, é essencial revisar a obra de Silvia Federici, O Calibã e a Bruxa. Em sua investigação, Federici buscou explicações sobre a origem da exploração social e econômica das mulheres para a consolidação do novo modelo econômico, o capitalismo. Nesse sentido, se estabelece a relação entre o tema e o campo do design, pois através dos artefatos e sua carga simbólica no espaço social é possível refletir sobre as estruturas sociais que historicamente validam a posição da mulher nas relações sociais.

A proposta da autora atentou para os aspectos da exploração e diferenças de poder entre mulheres e homens. Destacando que, as mulheres foram excluídas do desenvolvimento capitalista. A autora evidencia ainda, o trabalho não remunerado exercido pelas mulheres no lar, que considera como pilar sobre o qual se construiu a exploração dos trabalhadores assalariados. Sendo assim, é possível afirmar através da pesquisa da autora que a exploração do trabalho da mulher é uma decorrência de um processo da formação do espaço social, com o estabelecimento de divisões entre grupos de sujeitos. 
Federici (2017) atentou para a assimetria de poder entre mulheres e homens na sociedade capitalista ao ressaltar que não poderia ser atribuída à irrelevância do trabalho doméstico para a acumulação de capital. Uma vez que, a exploração do trabalho das mulheres nos lares foi essencial para o processo de acumulação e o desenvolvimento do capitalismo. Para isso, ainda há o processo que naturaliza os papeis sociais de acordo com o gênero. Conforme afirmado por Preciado (2014, p.26), "o sistema sexo/gênero é um sistema de escritura. O corpo é um texto socialmente construído". Nesse sentido, é possível ressaltar os marcadores da masculinidade e feminilidade que atuam nos sujeitos e são determinantes para os seus posicionamentos no espaço social. Os marcadores de gênero ressaltam a binaridade como uma expressão natural do sujeito e suas relações com o mundo. Calibã e a bruxa e sua abordagem histórica é primordial para o entendimento de aspectos que formam a sociedade. $\mathrm{O}$ livro retoma discussões acerca do processo de desenvolvimento da história e amplia o debate sobre a história das mulheres. Destaca os elementos presentes no surgimento do capitalismo e suas implicações para as mulheres na época e na contemporaneidade.

\section{As transformações das relações de gênero no desenvolvimento capitalista}

Silvia Federici iniciou sua pesquisa sobre às mulheres e o processo de desenvolvimento do capitalismo na década de 1970, O calibã e a bruxa é fruto dessa pesquisa. Nele a autora revisa o processo histórico e aborda as origens da exploração de gênero estabelecidas durante a formação capitalista. A pesquisa contribui para o entendimento da relação de poder existente entre o homem e a mulher, destaca as instituições e acontecimentos históricos que moldaram as relações de gênero no espaço social.

Em sua pesquisa, Federici destaca alguns fenômenos da acumulação primitiva que envolvem as mulheres, dentre eles estão o desenvolvimento de uma nova divisão sexual do trabalho, a exclusão das mulheres do trabalho assalariado e a reprodução da força de trabalho. A autora expõe os artifícios empregados, durante a passagem do feudalismo para o capitalismo, que contribuíram para a degradação da imagem da mulher, para o controle da reprodução e a exploração do seu trabalho. $\mathrm{Na}$ sua obra a autora expõe a guerra contra as mulheres estabelecida durante o processo de desenvolvimento capitalista.

A obra de Federici mostra como o controle empregado contra as mulheres tomou proporções cada vez maiores, resultando no estabelecimento de um regime patriarcal mais opressor comparado ao presente na sociedade pré-capitalista. A autora destaca que a aldeia medieval não era uma sociedade igualitária e que havia uma relação de poder entre os homens e as mulheres, porém as servas eram menos dependentes dos homens, havia uma menor diferenciação social, como também uma menor subordinação comparada com as relações desenvolvidas no processo de transição para o capitalismo. 
Um exemplo está na transformação da visão que a sociedade tinha do trabalho doméstico, na aldeia feudal a atividade doméstica não era desvalorizada, em contrapartida no sistema capitalista deixou de ser vista como um trabalho real, e incorporou um sentido de atividade natural da mulher.

A função reprodutiva das mulheres é um dos pontos utilizados para empregar o controle, tanto através do Estado como através da igreja. A autora destaca que, até certo período, em partes da Europa as mulheres exerciam o controle da reprodução, há registro do uso de contraceptivos e do aborto como práticas para controlar a função reprodutiva. Segundo Federici até certo momento, durante a Alta Idade Média, a igreja via essas práticas com indulgência, pois considerava a situação econômica dessas mulheres. Porém com a identificação de uma crise demográfica, em uma sociedade de um período de transição, o Estado e a Igreja passaram a reprimir e intervir na função reprodutiva das mulheres. A igreja passou a condenar e demonizar essas práticas enquanto o Estado, em certo momento, institui leis que interviam nas práticas de reprodução. É nesse contexto, de acordo com Federici, que a heresia era violentamente condenada pela igreja, e que no século $\mathrm{XV}$, a figura do herege tornou-se cada vez mais a figura da mulher, a bruxa para os inquisidores.

Ao apresentar o referido momento histórico focando na história da mulher, a autora descreve um processo longo, que durante séculos transformou negativamente a imagem da mulher. Percebe-se que o capitalismo é responsável por anular a participação efetiva da mulher nos espaços públicos, pois ao estabelecer tantos estigmas acerca de uma natureza construída, invisibilizou a mulher além de explorála dentro de um sistema monetário em que o seu trabalho no lar não era remunerado, as deixando dependentes dos homens da família. Condicionando assim o seu papel no espaço social.

É nesse contexto que a autora faz referência a divisão sexual do trabalho. Segundo Federici, as mulheres proletárias tinham que além do trabalho doméstico, trabalhar para o mercado, porém estava em curso uma crescente diferenciação entre o trabalho masculino e feminino que de acordo com o seu progresso modelava relações sociais diferentes e de maior desigualdade. A partir disso a autora expõe o processo gradual em que as mulheres perdem acesso a espaços sociais, e à medida que a sua imagem era demonizada e ridicularizada maior se tornava a diferença de poder exercida entre os gêneros.

Portanto, percebe-se que a exploração do trabalho e a violência aplicada, são parte de um processo de degradação da mulher. A partir da pesquisa de Federici, que expõe esse processo, é descrito de maneira clara as etapas e os responsáveis por moldar e transformar ao longo de séculos o imaginário social vinculado a mulher. A autora evidencia aspectos influentes para esse processo, como a literatura erudita e popular, que contribuía para naturalizar os marcadores da feminilidade, que a ela relacionava 
características pejorativas e contribuía para determinar as relações de gênero, presentes até na contemporaneidade.

Federici destaca uma mudança no modelo de feminidade que ocorreu no final do século XVIII. O novo modelo seria o perfil da "dona de casa", a autora descreve como "passiva, obediente, parcimoniosa, casta, de poucas palavras e sempre ocupada com suas tarefas" (FEDERICI, 2017, p.205). Diferente do modelo ao qual foram consideradas perigosas e demoníacas nos séculos anteriores. Federici (2017, p.205) descreve a imagem da feminilidade anterior sendo "selvagens, mentalmente débeis, de desejos insaciáveis, rebeldes, insubordinadas, incapazes de autocontrole". Essas ferramentas de classificação foram sendo moldadas de acordo com o interesse de quem detinha o poder na sociedade, então de acordo com as mudanças de objetivos econômicos, as ferramentas de controle em relação a figura da mulher foram transformadas.

Ao tratar da feminidade Beauvoir (1967) afirma ser um erro entendê-la como um dado biológico, e a classifica como um destino para a mulher imposto por seus educadores e pela sociedade. Nesse sentido, é importante destacar que é através do senso comum que se estabelece a noção de uma "dona de casa", da sua sensibilidade e vocação para as tarefas do lar. Dessa forma, ao relacionar com o aspecto histórico exposto por Federici é possível observar que o processo de socialização pode ser responsável por construir o imaginário formar o senso comum que reconhece e valida a feminilidade.

A investigação de Silvia Federici proporciona o conhecimento histórico do processo que institui em muitas sociedades uma imagem depreciativa da mulher. Dessa forma o seu estudo contribui, pois vai além do reconhecimento que há uma diferenciação de poder, a autora esclarece e expõe aspectos que permitem reconhecer concepções que são consequência dessa formação social. Compreender que o sexismo que faz parte do espaço social está além do reconhecimento. A pesquisa histórica é fundamental para tencionar as raízes da diferenciação de gênero, e a autora cumpri esse objetivo.

\section{Design e Gênero}

As discussões que envolvem gênero no campo do design são necessárias. Como afirma Rafael Cardoso (2016), é a comunidade que define o que o artefato quer dizer. Isso se deve ao fato de que além da sua funcionalidade prática, há um contexto histórico e cultural que afetam diretamente a percepção do usuário e do designer sobre o artefato. Segundo Margolin (2014) constata, existe uma importância em reconhecer o valor da experiência do usuário e do designer no desenvolvimento de artefatos. Dessa forma, os conceitos levantados por Federici são necessários para a discussão no campo do design. Visto que para estabelecer a relação entre gênero e design é importante a compreensão do que é entendido 
quando se fala em feminilidade e masculinidade e como isso é determinante para as relações sociais. Dentre elas, as relações de consumo.

“Devido à suposta função de procriação dos corpos femininos, as mulheres estariam envolvidas mais diretamente com a manutenção da espécie e em constante contato com seu "lado animal" (através do ciclo menstrual e seus desdobramentos), ao contrário dos homens. Esse pressuposto tende a legitimar uma liberdade maior aos homens para "tomarem conta" de projetos culturais." (BECCARI e RATI, 2020, p. 8)

Ao observar a construção da sociedade é possível afirmar que historicamente as mulheres foram privadas de ter participação na esfera pública e política. Nesse sentido, é possível entender que as consequências estão presentes na sociedade contemporânea, apesar de haver, na atualidade, uma participação maior de mulheres nas diversas esferas da sociedade.

No espaço social, é perceptível que há uma camada simbólica que determina a nossa percepção não apenas diante de artefatos, mas também do discurso que os acompanha. Para Margolin (2014), o incentivo em pesquisas com o tema de uso de produtos é fundamental para compreender a relação entre designers, produtos e usuários. É a partir de pesquisas que se torna possível entender essa relação, seus impactos para a sociedade e como evitar que o designer exerça um papel de agente na reprodução de estruturas sociais que mantém os ideais de desigualdade presentes nas relações sociais.

\section{Considerações Finais}

Neste artigo estudou-se a história das mulheres na transição para o capitalismo. Por meio da contribuição de Silvia Federici, que propôs escrever sobre esse período da história analisando o desenvolvimento capitalista através da história das mulheres. A autora apresenta fatos históricos e análises que proporcionam o conhecimento de acontecimentos históricos que modelaram ao longo das décadas a forma com que as mulheres foram subjugadas e exploradas.

Deixa claro que o papel atribuído as mulheres fica condicionado aos interesses econômicos e sociais de grupos sociais e instituições que mantinham o poder na sociedade. A influência que o Estado e a Igreja desempenharam para fortalecer a relação de poder entre os gêneros são um indício de que as mulheres, durante o período, foram vítimas de um modelo econômico que se beneficiou da exploração de determinados grupos de sujeitos para se estabelecer como hegemônico. Isso resultou na subjugação das mulheres, que ainda está presente na contemporaneidade. 
Observou-se que a relação entre gênero e design pode refletir os aspectos das estruturas sociais que são reflexo de uma construção histórica responsável por atribuir às mulheres um papel inferior no espaço social. É importante destacar a visão de Forty (2007) sobre a escassa atenção dada a influência do design na nossa forma de pensar. Segundo o autor, o design provoca efeitos muito mais duradouros do que os produtos da mídia, por exemplo, pois ele dá formas tangíveis e permanentes às ideias sobre quem somos e como devemos nos comportar. Sendo assim, por ser um campo que está ligado a sociedade e a sua cultura, o design pode refletir os traços que marcam a estrutura social. Portanto, o estudo de gênero no campo do design é fundamental para desmontar os aspectos, presentes nesse campo, que contribuem para uma relação desigual de poder entre grupos sociais.

\section{Referências}

BECCARI, M; RATI, B. Estereótipos de gênero e apelos retóricos no design gráfico um modelo de análise. Rio de Janeiro: Estudos em Design, 2020.

BEAUVOIR, Simone de. Segundo Sexo, Vol.2: A Experiência Vivida, Difusão Europeia do Livro, 1967.

CARDOSO, Rafael. Uma introdução à história do design. São Paulo: Blücher,2008.

CARDOSO, Rafael. Design para um mundo complexo. São Paulo, UBU Editora,2016.

FORTY, Adrian. Objetos de Desejo design e sociedade desde 1750. Cosac Naify,2007.

FEDERICI, Silvia. Calibã e a bruxa: mulheres, corpo e acumulação primitiva. São Paulo: Elefante, 2017. MARGOLIN, Victor. Políticas do artificial: ensaios e estudos sobre design, Rio de Janeiro: Record, 2014. PRECIADO, Beatriz. Manifesto Contrassexual; tradução de Maria Paula Gurgel Ribeiro. São Paulo: n-1 edições, 2014. 